\title{
EDUCATIONAL RESEARCH IN ACTION
}

\section{The Implementation of Virtual Instruction in Relation to X-ray Anatomy and Positioning in a Chiropractic Degree Program: A Descriptive Paper}

\author{
Perry O. Rush, DC, William R. Boone, PhD, DC, Sherman College of Straight \\ Chiropractic
}

This article provides information regarding the introduction of virtual education into classroom instruction, wherein a method of classroom instruction was developed with the use of a computer, digital camera, and various software programs. This approach simplified testing procedures, thus reducing institutional costs substantially by easing the demand for manpower, and seemed to improve average grade performance. Organized files with hundreds of digital pictures have created a range of instructor resources. Much of the new course materials were organized onto compact disks to complement course notes. Customizing presentations with digital technology holds potential benefits for students, instructors and the institution. ( $\mathrm{J}$ Chiropr Educ 2009;23(1):40-46)

Key Indexing Terms: Instructional models, teaching, virtual systems, teaching methods

\section{INTRODUCTION}

Modern technology has altered classroom instruction. As instructors have discovered and implemented state of the art technology in industry and academics, it has been observed that student learning has also been enhanced. ${ }^{1-4}$ Approaching education in this manner has resulted in a change in the attitude of students and their respective institutions of higher education, including professional institutions, to engage in contemporary methods. ${ }^{5,6}$ Moreover, such a change is required to keep pace with the culture of learning emerging among the younger generation of baccalaureate and post-graduate students. ${ }^{7,8}$

Within our chiropractic program a large portion of the instruction is didactic, especially relative to the basic sciences. However, as with other health care disciplines, the practical implementation of chiropractic care requires extensive training in visualization in regard to interpreting radiographic images and other physical assessments. ${ }^{9}$ Thus, the nature of the didactic approach has necessitated extensive lecture time, coupled to exhaustive involvement of the clinic staff to serve as the resource for student preparation for examinations. Based on these circumstances, it became apparent that a transition to a more effective method of student preparation in the clinical sciences was required to keep pace with the changing attitudes among students regarding learning methods. We report here on an approach that has resulted in perceived benefits to students, faculty, and the institution. This paper describes the methods and results obtained from implementing a current technological methodology while moving away from the customary didactic approach to student instruction.

\section{METHODS}

The methods described below were applied to several different courses, including: upper cervical $\mathrm{x}$-ray positioning, full spine $\mathrm{x}$-ray positioning, upper cervical rationale, Blair x-ray methodology, and $\mathrm{x}$-ray anatomy. Whereas this approach served to enhance the availability of resource information for the several courses mentioned, it substantially 
changed the mode of teaching in regard to x-ray anatomy and upper cervical $\mathrm{x}$-ray positioning. Thus, the actual quantitative improvement within the $\mathrm{x}$ ray anatomy course has been reported in this paper. A "picture cruise" relative to upper cervical $\mathrm{x}$-ray positioning was also developed (Fig 1A-1D), and the course syllabus can be accessed at http://www. sherman.edu/faculty/rush/syllabi/index.html.

\section{Image Development}

The goal was to merge image development with image access. This process has been summarized in Figure 2. The first aspect, image development, was accomplished by taking digital pictures with a Pentax Optio 450 camera (Pentax, Nashville, TN) The benefits afforded by this particular camera included ease of use, a dependable rechargeable lithium-ion battery D-L17, and battery charger, making the camera cost effective. Digital images of $\mathrm{x}$-rays were acquired by illuminating them on
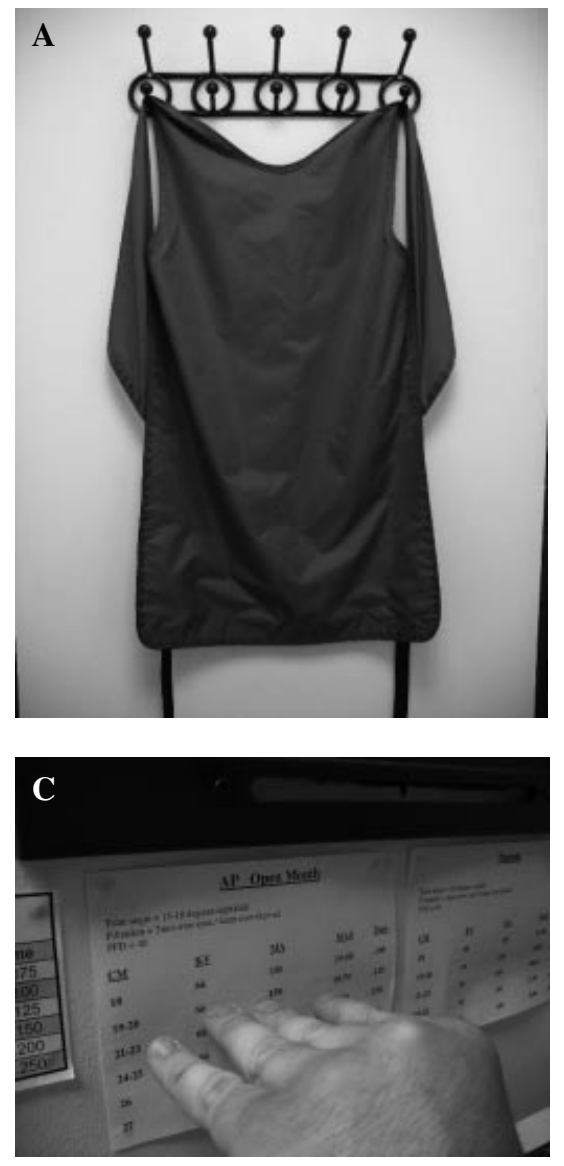

an x-ray view box. Digital images of boney spines and other objects were also obtained. After x-ray images were photographed, using a standard setting with zoom-in capability for close up shots when needed, the images were transported to a designated file housed on a Dell desktop computer processor (512 MB, $3 \mathrm{GHz}$ ), equipped with Microsoft Word XP Professional (Microsoft Corp, Redmond, WA) and a compact disk (CD) burner. Using standard Microsoft Power-Point (Microsoft Corp, Redmond, WA) software, classroom presentations were developed from the repository of digital images and then transported to CDs for use by students. This provided continuity between information provided to students and classroom instruction.

\section{Image Access}

In order to minimize difficulty regarding $C D$ access, a user-friendly auto-launch CD was created for students using technology compatible with the
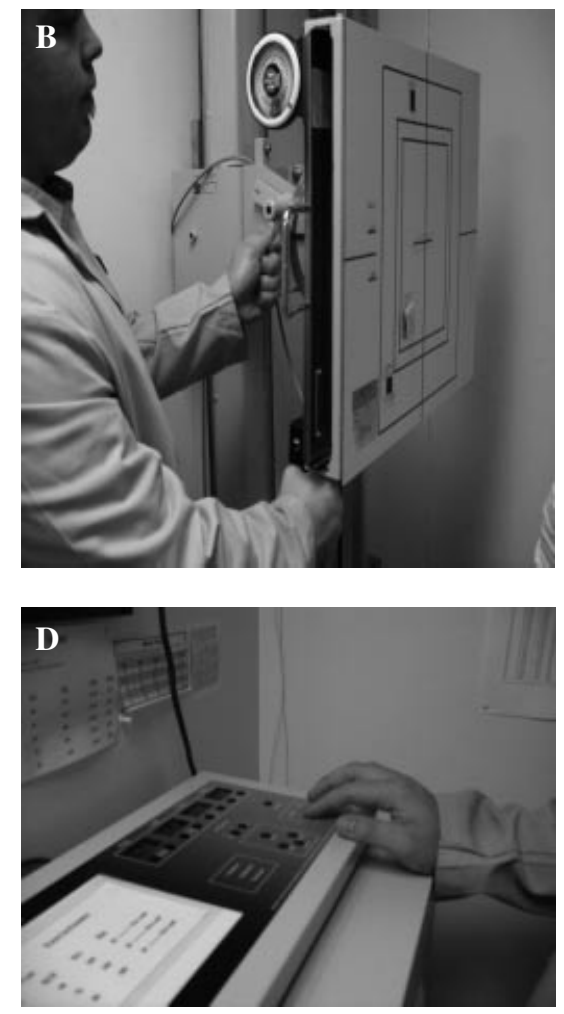

Figure 1. (A) Lead vest placed on each patient when an anterior-posterior cervical $x$-ray is taken. (B) Positioning the $x$-ray bucky as one of the many steps in the base posterior $x$-ray view picture "cruise." $(C)$ Setting the factors on the chart from the caliper measurement as one of the steps in the base posterior $x$-ray view picture "cruise." (D) Mock exposure as one of the steps in the base posterior x-ray view picture "cruise". 


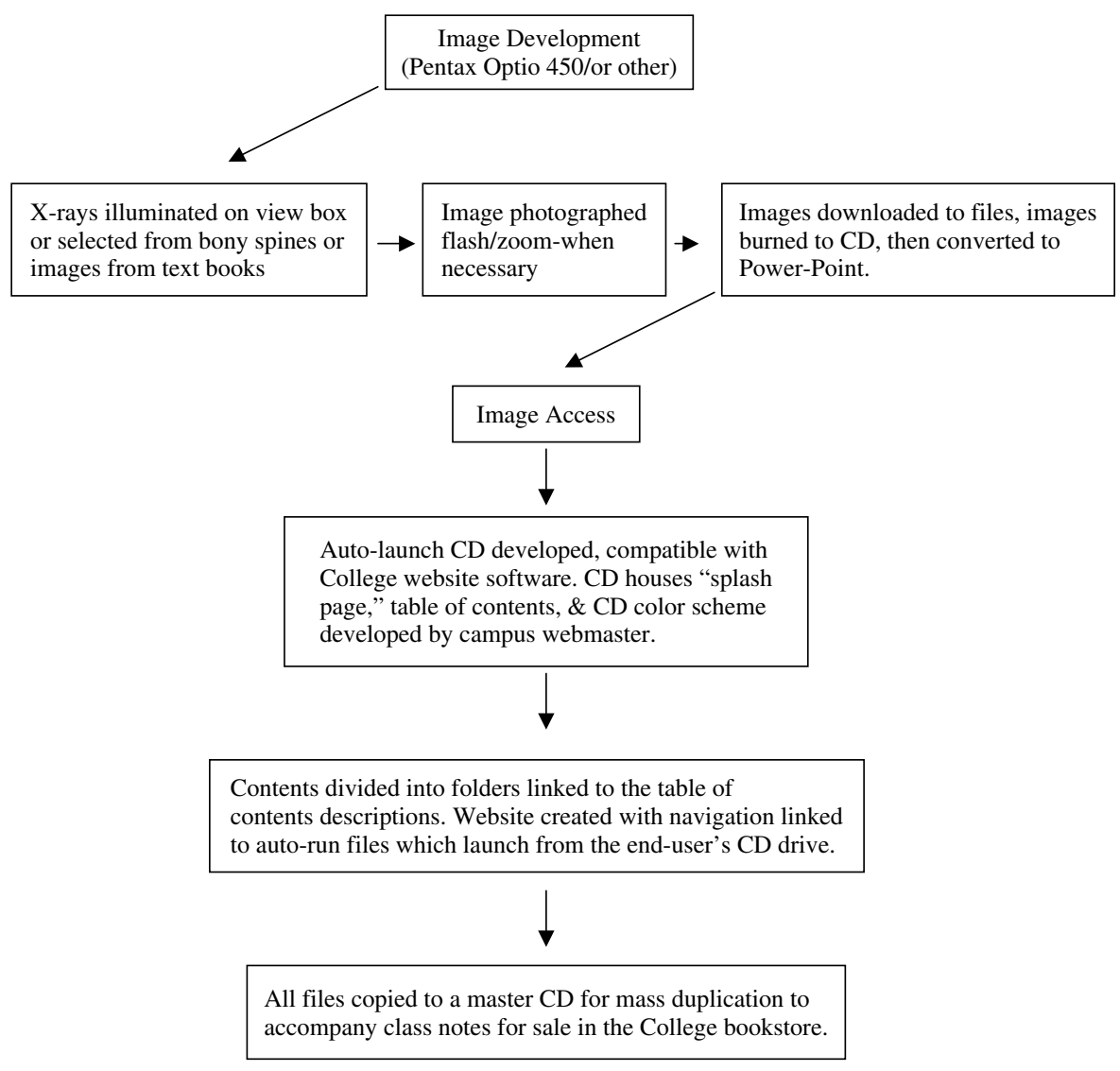

Figure 2. Flowchart for x-ray anatomy image development and student access.

college website software. This included a splash page (the first page launched when the user inserts the CD). A table of CD contents was also created which displayed when the $\mathrm{CD}$ was inserted into the computer for use. These additions included a graphic representative of the course subject. The color scheme "look and feel" was then incorporated throughout the $\mathrm{CD}$ by a member of the faculty handling all CD production and formatting. These embellishments were added by first downloading the $\mathrm{CD}$ containing all the raw materials (documents and photos), to designated computer files. Through the use of a web editor (Dreamweaver, model CS3, Adobe Systems Inc, San Jose CA) or FrontPage, (Model 2003, Microsoft Corp, Redmond WA) a "website" for the contents, complete with index (or splash) page and table of contents was created. For user navigation purposes, the contents were divided into appropriate folders which were then linked to the content and table of contents descriptions.

Once the website was created and navigation was linked and checked, several auto-run programming files were created which allowed the $\mathrm{CD}$ to automatically launch when inserted into the end-user's $\mathrm{CD}$ drive. To complete the image access facility, the website files, including the auto-run files, were copied to a master $\mathrm{CD}$, which was then used for the process of mass duplication of the CDs in question. The "look and feel" of the CD was developed by the strategic use of graphics and background colors chosen to unify the look. The graphics and backgrounds were embedded into each page of the "website" through the use of hypertext markup language (HTML). Using Acoustica CD/DVD Label Maker, version 2.4.1 creator software (Acoustica Inc, Oakhurst, CA). The label was designed using graphics and colors that would compliment the thematic design scheme used on the internal contents of the $\mathrm{CD}$. The labels were then printed and attached to the CDs which were then placed in paper CD sleeves, making them ready for sale in the college bookstore.

\section{RESULTS}

\section{Benefits}

Accessing a specific, read only website address, now allows instructors and students to view the CDs for classroom or personal use. These developments 
are anticipated to improve the learning process by having a reference upon which all students learn from the same standard. This has also afforded the instructor more time for other scholarship by referring students to the $\mathrm{CD}$ images, rather than repeating the information many times over. This repository of information has also been used in other areas of instruction when course syllabi have been restructured or ameliorated. Moreover, an assessment of the cost of supporting this course routinely called for two or more assistants, x-ray duplications and replacements. Estimates for that level of support were approximately $\$ 22,000$ per year. Currently, the same course is supported by approximately $50 \%$ of that cost.

\section{Course Grade Improvement}

While the yearly mean was at the "C" level in $\mathrm{x}$ ray anatomy in 2004, prior to implementation of the technology described herein, each subsequent year's class averages increased consistently to the "B" level, with overall averages becoming significantly higher (Mann-Whitney Test for ordinal data, $\mathrm{p}=$ 0.035) when comparing 2007 to 2004, and 2007 to the subsequent year, $2005(\mathrm{p}=0.038)$, the first year of implementation of the new approach, (Fig 3). However, though the mean class grade for the year 2007 continued to improve, it was not significantly above 2006, as the grades for these two years were closely matched.

Figures 4-5 show examples of this approach to virtual instruction. The major benefit of this type of design is that photos of real bone can be laid parallel to x-ray images for ease of comparison. As well, the CDs become available for other instructors who teach related courses, or as described in this paper, others seeking alternative approaches to instruction at their respective institutions.

The x-ray anatomy $\mathrm{CD}$ is now an organized collection of 371 labeled $\mathrm{x}$-ray views. It contains 8 power point picture presentations identifying every anatomical aspect corresponding to classroom notes. It also contains 92 digital pictures of real bone specimens from numerous angles taken from $\mathrm{x}$ rays. Once downloaded into computer files, each image can be selected from a growing repository to customize presentations per the requirements of different courses. Additionally, the power point "picture cruise" of each step for all cervical x-ray positions now provides extra preparation for students preparing for the clinic entrance examination. It also allows for classroom to implementation consistency and provides easy access for course review committees and the clinic health center faculty and staff.

\section{DISCUSSION}

Drawing upon technology that spanned the previous decade, ${ }^{10,11}$ this advancement in classroom instruction and presentation style is believed to have led to a greater appreciation of the course content, and student learning. This belief is based on anecdotal reports from students and instructors welcoming the approach. However, future studies will have to be conducted that investigate this belief through survey instruments and other assessments of all of the courses utilizing this technology.

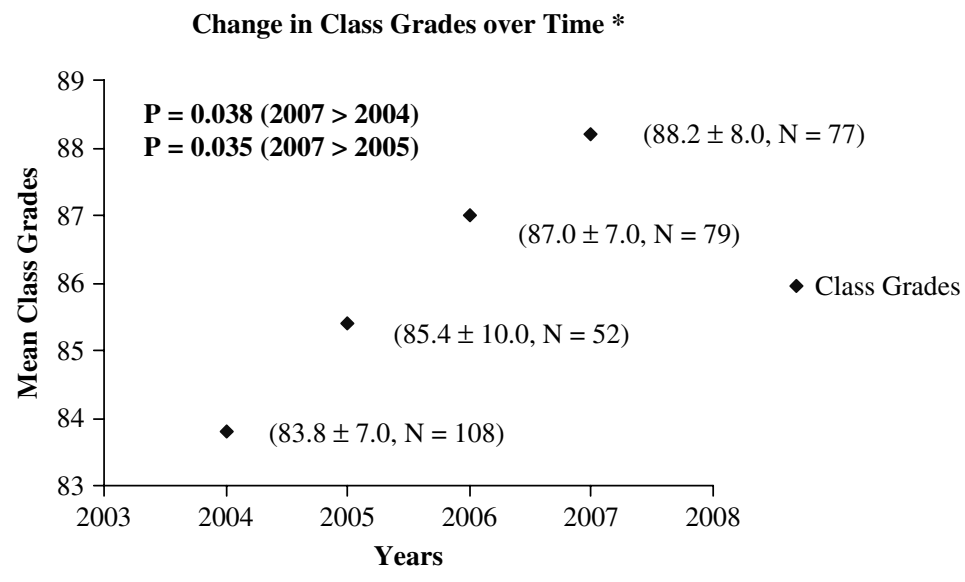

Figure 3. Radiographic anatomy course grades for each year (2004-2007) were averaged (4 classes per year) and compared for statistical differences (Mann-Whitney Test for ordinal data, $p<0.05$ ). 

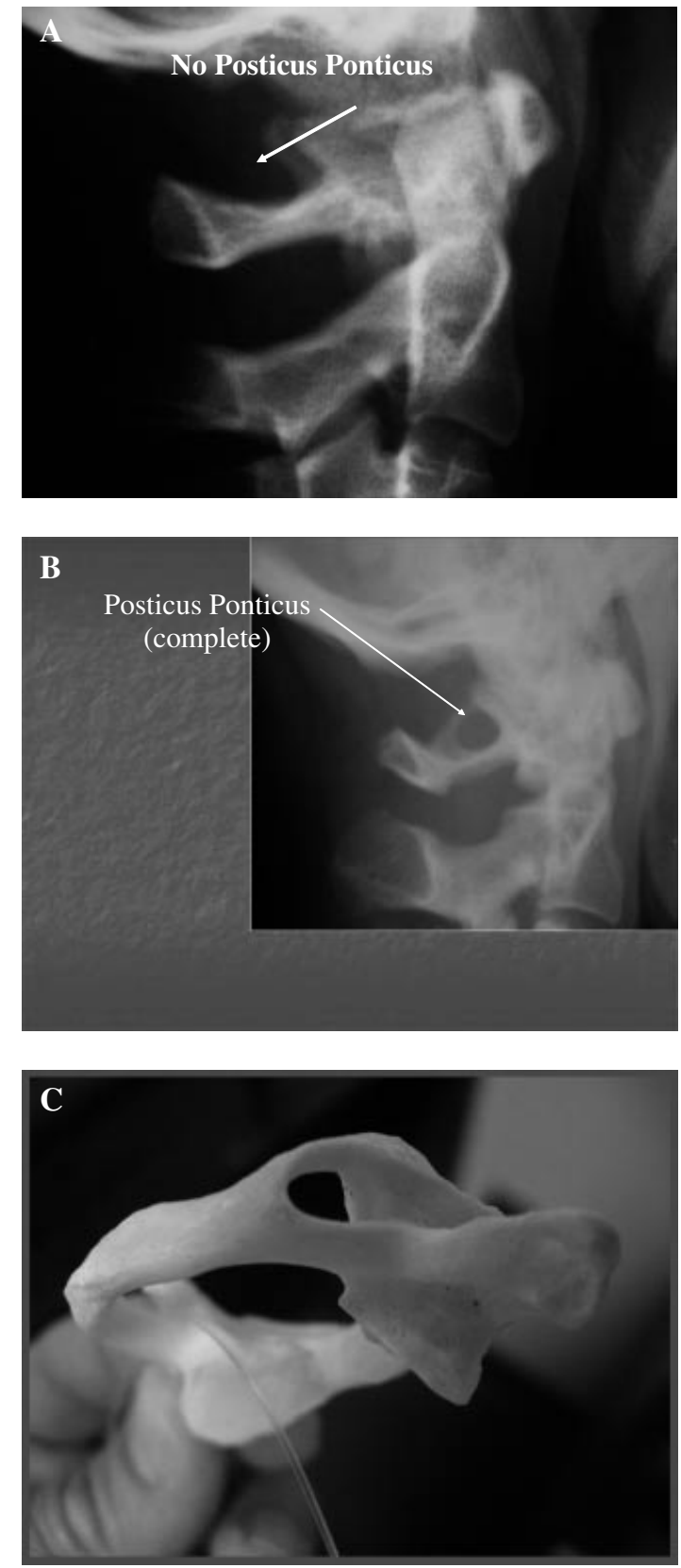

Figure 4. (A) Radiograph showing the absence of posticus ponticus. (B) Radiograph showing presence of a complete posticus ponticus. (C) This real bone atlas has a complete posticus ponticus.

This approach arose as a response to one particular problem ultimately giving rise to a number of benefits. For example, as x-rays used by students in many courses became old, scratched, or lost, it became more and more difficult to replace them. Consequently, each quarter fewer and fewer good quality x-rays were available for students' use. Electronic searches provided some resources but lacked the diversity that was being sought. Moreover,

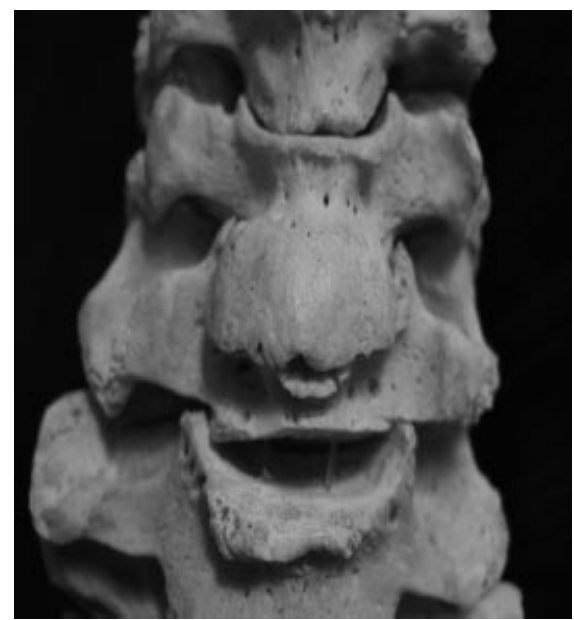

Figure 5. Real bone unhealthy cervical spine viewed from the anterior.

accessibility improved as students could review the same digital image of a selected $\mathrm{x}$-ray projected on a large screen. This, of course, is routine in learning institutions, allowing instructors to customize presentations from personal resources originating from the instructor's personal and growing repository.

Should a particular anatomical aspect become desirable to view, such as a posticus ponticus (Fig 4A-4C) from a real bone specimen, this would allow the student to visualize it from different angles on the same slide. That is, a specimen difficult to find in a text is now easily accessible. Moreover, for the instructor, there is no copyright infringement since it is part of a $\mathrm{CD}$ purchased as a complement to course notes. Moreover, a digital picture image of an x-ray which can be inserted into a power point presentation provides substantial benefits for the instructor as well as students. Previously, hard copy x-ray films were copied on expensive copiers. It is now more efficacious to take an $\mathrm{x}$-ray of interest, place it on a view box and take a picture with a quality digital camera. Once this image is downloaded into a computer file it can be used many times for other presentations. Consequently, in academics, hard copy x-rays are likely to become obsolete. As well, digital x-ray will likely surpass the digital camera. However, the digital camera still remains a useful technology for customized presentations unique to each instructor.

Figures 1A-1D are examples of virtual instruction. Upper cervical $\mathrm{x}$-ray positioning uses an organized set of 20 procedures or steps for each cervical film taken. The x-ray facility requires specificity to procedures in each of our college's three x-ray rooms. Thus, procedures for three different $\mathrm{x}$-ray 
machines must be mastered. The new student is soon confronted with extensive detail which changes for each x-ray patient setup. Thus, the digital "picture cruise" of every step for each cervical film was organized onto a $C D$ with accompanying notes that are accessible for a nominal fee. These picture cruises are viewed in the classroom and then practiced repetitively in the clinical setting. Importantly, the material can be reviewed at the student's leisure via their personal computer or the college computer center. Additionally, this material can be reviewed over the next several quarters before taking the clinic entrance exam at times when it is difficult to gain access to the x-ray rooms for practice. As well, they provide a readily available review before students x-ray new patients.

This approached has been welcomed, anecdotally, by the students, and instructors, and is underpinned to some extent by the significant grade changes observed between the years between 2007 and 2004 and 2005. However, several variables may be influencing this perceived outcome. Consequently, future reports on the significance of introduction of virtual technology into this particular course and others using the same technology will be analyzed through structural equation modeling (SEM). ${ }^{12-14}$ The SEM approach incorporates the general linear regression model, which includes multiple regression but also allows broader assumptions and stronger indicators of which variables are exerting the primary influences over the outcomes being measured. ${ }^{15}$

While this paper has dealt with the personal experience of one faculty member, through observation, others have initiated similar approaches to advance digital technology applied to the educational process. ${ }^{16-18}$ As well, the campus X-ray department is developing a repository of digital images obtained through the clinic health center. It seems apparent that a repository of digital images in other courses unrelated to X-ray will also provide similar advantages for other instructors and their students.

\section{CONCLUSION}

This paper describes one method of development and implementation of technology applied to didactic and practical instruction. The use of a digital camera permits flexibility and spontaneity relative to capturing images for instructional purposes. High quality images are attainable, allowing for presentations to be developed that provide visual scenarios beyond the scope of textbooks. The technology has reduced the cost to run the course, allowing funds to be dedicated to other educational enhancements. Methods are currently being developed to regularly assess the outcome of this approach in terms of changes relative to student comprehension of material and successful completion of examinations that test their level of understanding.

\section{CONFLICTS OF INTEREST}

The authors have no conflicts of interest to declare.

\section{ACKNOWLEDGEMENTS}

The authors would like to thank Joy A. Gaylor, assistant professor of clinical sciences, instructional designer/webmaster at Sherman College of Straight Chiropractic. Her insight, talents, and knowledge of chiropractic were a great contribution to the success of the implementation of the virtual instruction described in this article.

Received, March 25, 2008

Revised, May 20, 2008 and August 31, 2008

Accepted, September 16, 2008

Address correspondence to: William R. Boone, DC, $\mathrm{PhD}$, Sherman College of Straight Chiropractic, 2020 Springfield Rd, Spartanburg, SC 29304, 864-578-8770 ext 279, rboone@sherman.edu

\section{REFERENCES}

1. Krentler KA, Willis-Flurry LA. Does technology enhance actual student learning? The case of online discussion boards. J Educ Bus 2005;80(6):316.

2. Bocchi J, Watson V, Weyand F. Technology-enhanced learning in industry and higher education: preliminary report on a gap analysis [commentary on the internet]. University of North Carolina: The Technology Source Archives; 1999. Available from (http://ts.mivu.org/ default.asp?show=article\&id=1034).

3. Cobb P, Confrey J, di Sessa A, Lehrer R, Schauble L. Design experiments in educational research. Educ Res 2003;32(1):9-13.

4. Eugenio V. Implementing learning technologies? Corp Univ Rev 1998;6(2):33-8.

5. Gouvela-Oliveira A, Rodriques T, De Melo FG. Computer education: attitudes and opinions of first-year medical students. Med Educ 1994;28(6):501-7.

6. Dorup J, Schant HM, Ribe LR. Integrating IT-supported and traditional learning in a health informations course. 
In: Ribeiro LM, Marques dos Santos J, editors. Proceedings of the $8^{\text {th }}$ International European University Information Systems Conference; 2002 Jun 19-ss; Porto, Portugal. Porto: Universidade do Porto; 2002:106-7.

7. Hovenga EJ. Using multi media to enhance a flexible learning program: lessons learned. Proc AMIA Symp1999:530-534.

8. Mee-Kyeong L, Ibrahim E. The effect of sciencetechnology-society teaching on students' attitudes toward science and certain aspects of creativity. Int J Sci Educ 2007;29(11):1315-27.

9. Nilsson TA, Hedman LR., Ahlqvist JB. A randomized trial of simulation-based versus conventional training of dental student skill at interpreting spatial information in radiographs. J Soc Simul Healthc 2007;2(3):164-9.

10. Anon. The evolution of digital publishing in higher education. Tech Horiz Educ 2003;30. Available from: www.thejournal.com/articles/16271.

11. Staley DJ. Adopting digital technologies in the classroom. Educause Q 2004;27(3). Available from: http:
//connect.educause.edu/Library/EDUCAUSE+Quarterly /AdoptingDigitalTechnologi/39875.

12. Anderson C, Gerbing DW. Structural equation modeling in practice. A review and recommended two-step approach. Psychol Bull 1988;103(3):411-23.

13. Bentler PM, Chou CP. Practical issues in structural equation modeling. Soc Meth Res 1987;16(1):78-117.

14. Chen FKA, Bollen P, Paxton P, et al. Improper solutions in structural equation models. Causes, consequences, and strategies. Soc Meth Res 2001;29:468-508.

15. McDonald RP, Ho, MH. Principles and practice in reporting structural equation analyses. Psychol Meth 2002;7:64-82.

16. Foreman J. Next-generation educational technology versus the lecture. Educause Rev 2003;38(4):20.

17. Henderson K. On line and on paper: Visual representations, visual culture and computer graphics in design engineering. Cambridge: MIT Press; 1999.

18. Staley DJ, Cress WD. The university as a model of technological balance. Bull Sci Technol Soc 1998;18(1):19-21. 